Gut, 1971, 12, 34-39

\title{
The influence of mesenteric denervation on the inhibition of gastric secretion by fat in the intestine
}

\author{
JAIME ISAZA, KYOJI SUGAWARA, JOHN CURT, AND E. R. WOODWARD \\ From the Department of Surgery, University of Florida College of Medicine, Gainesville, Florida 32601, USA
}

SUMMARY The inhibitory effect of fat in the upper small intestine was studied in dogs prepared with a Heidenhain pouch, gastric fistula, and jejunal fistula. Gastric secretion was stimulated by a constant intravenous infusion of pentagastrin, and emulsified olive oil was introduced into the jejunum. The small intestine of the dog was denervated by complete transection of the mesentery except for the superior mesenteric vessels. After intestinal denervation inhibition of the vagally innervated stomach was almost abolished while that in the Heidenhain pouch was unchanged. It is concluded that either autonomic innervation is important in the formation of enterogastrone or, more likely, that efferent inhibitory fibres in the vagus to the stomach act synergistically with enterogastrone.

Pavlov (1910) in his classic monograph describes the experiments of Khizhin, Lobasov, and Sokolov, demonstrating that fat introduced into the duodenum reduces gastric secretion. This finding has been confirmed by many workers and has been attributed to a humoral mechanism, 'enterogastrone' (Kosaka and Lim, 1929-30). Subsequent work has indicated that the intestine plays a key role in inhibiting gastric function, both motor and secretory. This regulation is not accomplished by a single mechanism, but by many, including both autonomic nervous and endocrine mechanisms. The inhibitory effect of fat on gastric secretion cannot be fully accounted for by the known polypeptide hormones (Johnson and Grossman, 1969). The present experiment was undertaken to investigate the possibility that the autonomic nervous system might have a significant role in the 'enterogastrone' mechanism by which fat in the intestine inhibits gastric secretion.

\section{Method}

Five mongrel dogs weighing 15 to $18 \mathrm{~kg}$ were prepared by a one-stage aseptic operative procedure.

A Heidenhain (denervated fundic) pouch was constructed and drained to the exterior by a stainless steel Dragstedt cannula (Dragstedt, Haymond, and Ellis, 1933). A gastric fistula was then created in the remaining stomach by inserting a Thomas

Received for publication 20 July 1970. cannula in the most dependent portion of the greater curvature (Thomas, 1941). Lastly, an intestinal fistula was instituted by placing a Gregory cannula in the jejunum 6 in. distal to the ligament of Treitz (Gregory, 1950). The animals were permitted a period of four weeks or longer for recuperation before experiments were begun.

Animals were fasted for 18 hours before each experiment, and were not studied on successive days. Each dog was placed in a Pavlov stand and gastric juice collected by gravity from the gastric fistula cannula and the Heidenhain pouch cannula. A venous catheter was placed and gastric secretion stimulated by a continuous intravenous infusion of pentagastrin $^{1}$ in a dose of $0.5 \mu \mathrm{g} / \mathrm{kg} /$ hour. Pentagastrin was made up by adding $37.5 \mu \mathrm{g}$ to $100 \mathrm{ml}$ of physiological saline and was infused with a peristaltic pump. A plateau of gastric secretion was established, usually by 90 minutes; the level reached was $30-60 \%$ of maximum in all dogs.

When the plateau of gastric secretion was well established in both the gastric fistula and Heidenhain pouch, $15 \mathrm{ml}$ of a $50 \%$ olive oil emulsion ${ }^{2}$ in normal saline was slowly introduced through the Gregory cannula into the proximal jejunum during a period of 15 minutes. The fat infusion into the jejunum very occasionally induced retching or vomiting;

${ }^{1}$ Gastrin pentapeptide supplied by Project Services Division of Ayerst Laboratories, New York.

$22 \%$ Colloid magnesium aluminium silicate (Veegum, R.T. Vanderbilt Co, New York) was used as an inorganic emulsifier. 
whenever this occurred the experiment was terminated. The pentagastrin infusion was maintained at the same rate for an additional two hours while gastric secretion was collected every 15 minutes from both the gastric fistula and the Heidenhain pouch. Acidity of the gastric juice was determined by titrating with $0 \cdot 1 \mathrm{~N}$ sodium hydroxide to $p \mathrm{H} 7 \cdot 0$ using a Beckman model $96 p \mathrm{H}$ meter; gastric secretion was expressed as milli-equivalents of hydrochloric acid per 15 minutes.

Control infusions of pentagastrin were performed for periods of four hours in all animals and in every instance the plateau remained constant. The emulsifier alone was found to have no effect on gastric secretion. Olive oil and corn oil without emulsifier inhibited gastric secretion comparably, but nausea and retching were more frequent.

Twenty-four-hour collections of gastric secretion were obtained for periods of 10 to 20 days in each of the five dogs. Collection bags were attached to the Heidenhain pouch cannulas and the animals were maintained on a diet which was constant both in composition and amount. After electrometric titration gastric secretion was expressed as milliequivalents of $\mathrm{HCl}$ per day.

After completion of the above experiments the animals were laparotomized and mesenteric denervation was carried out as follows: the superior mesenteric artery and vein were isolated distal to the inferior pancreaticoduodenal and common colic arteries and veins. The small bowel mesentery was completely transected and the adventitia cleaned off the mesenteric vessels. The jejunum at the ligament of Treitz and the ileum at the ileocaecal valve were transected and re-anastomosed. A full-thickness biopsy of the jejunum was taken at this time and the mesentery was repaired (Fig. 1).

Six weeks later gastric secretory studies were resumed and the above protocol was repeated. The jejunum was re-biopsied at the time of sacrifice six to eight months after mesenteric denervation. Statistical analysis was done on gastric secretory data and the significance of the difference between the means of unpaired values was determined using Student's $t$ test (Snedecor and Cochran, 1967).

\section{Results}

Sixty-two experiments were performed before and 74 after mesenteric denervation in the five dogs. Fat in the form of an olive oil emulsion significantly inhibited $(P<0.01)$ the pentagastrin-stimulated secretion of both a vagally innervated gastric fistula (Fig. 2) and a vagally denervated Heidenhain pouch (Fig. 3). This inhibition usually lasted for 90 minutes; the degree of inhibition averaged $69.7 \%$ in the gastric

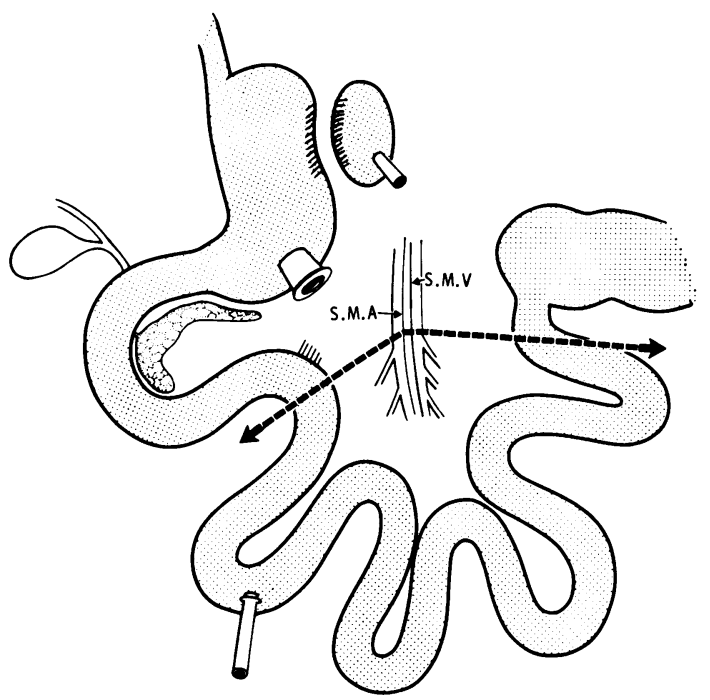

FIG. 1. Schematic representation of the surgical procedure. Broken arrows indicate the level of mesenteric denervation and intestinal transection.

fistula and $50 \%$ in the Heidenhain pouch (no significant difference statistically).

After mesenteric denervation the gastric fistula secretion was inhibited by only $23.5 \%$ (Fig. 4). This change from the studies before denervation proved to be statistically significant $(P<0.01)$. The Heidenhain pouch secretion after mesenteric denervation was inhibited by $40 \%$ (Fig. 5); this proved to be not significantly different from the inhibition observed in the studies before denervation.

Twenty-four-hour collections of gastric juice from the Heidenhain pouch demonstrated a significant increase after mesenteric denervation in four of the five dogs (Table I). This change was noted immediately, and was present as late as eight months after mesenteric denervation (Fig. 6). Study of the jejunal biopsies indicated no change in the microscopic appearance six to eight months after mesenteric denervation.

\section{Discussion}

There are many reports demonstrating that fat in the intestine inhibits the gastric secretory response to both endogenous and exogenous gastrin (Sircus, 1958; Gregory and Tracy, 1959; Konturek and Grossman, 1965; Bibler, Harkins, and Nyhus, 1966; Swan, Konturek, Jacobson, and Grossman, 1966; Debas, Bedi, Gillespie, and Gillespie, 1969; Windsor, 


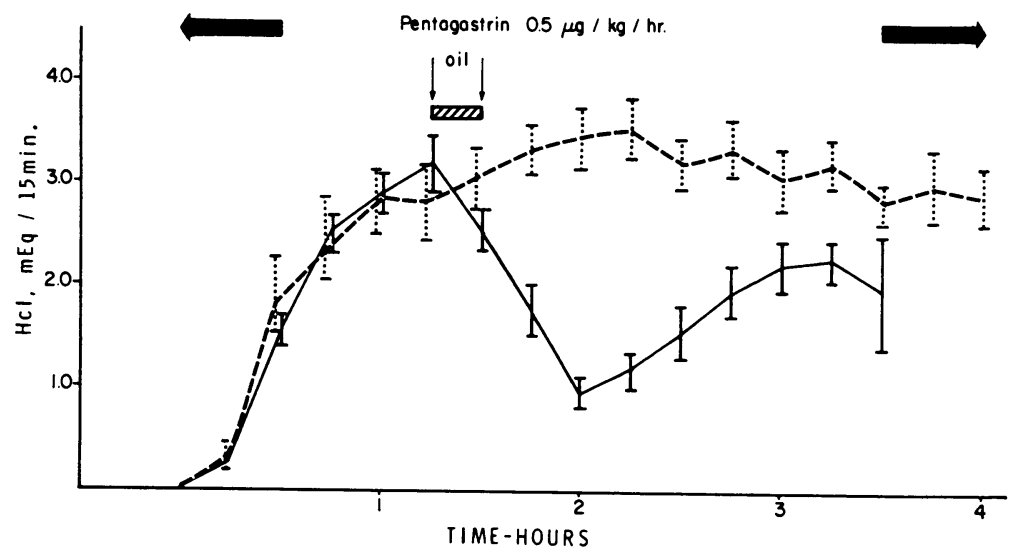

FIG. 2. Inhibitory effect of intrajejunal instillation of $15 \mathrm{ml}$ of emulsified olive oil on the pentagastrin-stimulated gastric fistula secretion before mesenteric denervation. Mean of 13 control (broken line) and 25 oil experiments (solid line) in five dogs. Vertical bars indicate standard error of the mean.

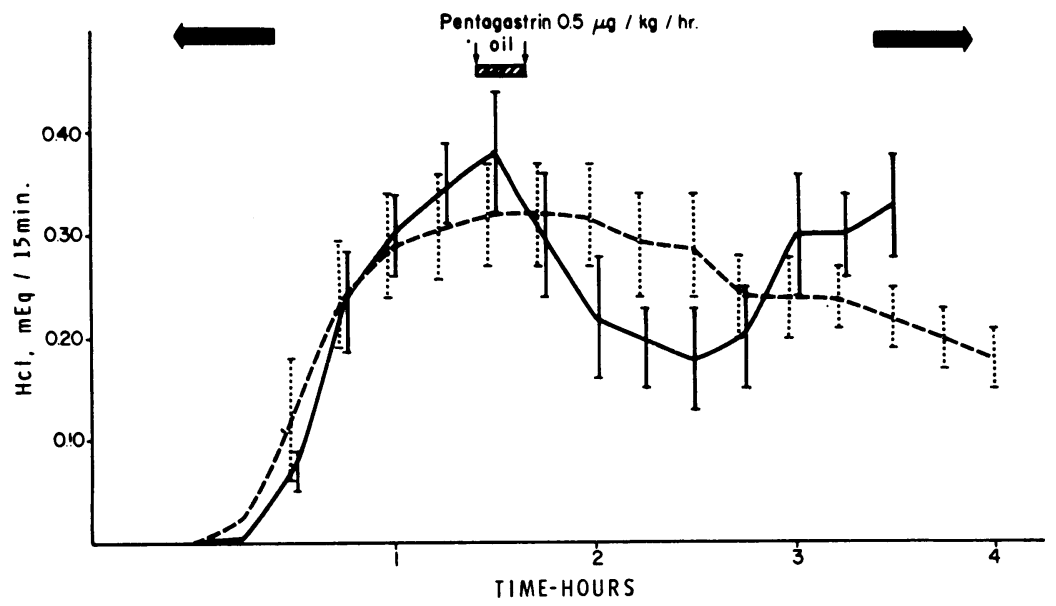

FIG. 3. Inhibitory effect of intrajejunal instillation of $15 \mathrm{ml}$ of emulsified olive oil on the pentagastrin-stimulated Heidenhain pouch secretion before mesenteric denervation. Mean of nine control (broken line) and 15 oil experiments (solid line) in five dogs.

\begin{tabular}{|c|c|c|c|c|c|c|}
\hline Dog & $\begin{array}{l}\text { No. of } \\
\text { Collections }\end{array}$ & $\begin{array}{l}\text { Before Denervation } \\
\text { (m-equiv } \mathrm{HCl} \pm S E M)\end{array}$ & $\begin{array}{l}\text { No. of } \\
\text { Collections }\end{array}$ & $\begin{array}{l}\text { After Denervation } \\
\text { (m-equiv } \mathrm{HCl} \pm S E M)\end{array}$ & $\begin{array}{l}\text { Percentage } \\
\text { Change }\end{array}$ & $P$ \\
\hline $\begin{array}{l}\mathbf{A} \\
\mathbf{B} \\
\mathbf{C} \\
\mathbf{D} \\
\mathbf{E}\end{array}$ & $\begin{array}{l}13 \\
10 \\
14 \\
15 \\
17\end{array}$ & $\begin{array}{r}38.21 \pm 3.38 \\
52.20 \pm 2.98 \\
9.46 \pm 0.55 \\
20.54 \pm 1.61 \\
40.08 \pm 3.06\end{array}$ & $\begin{array}{l}18 \\
15 \\
20 \\
19 \\
20\end{array}$ & $\begin{array}{l}60 \cdot 03 \pm 2 \cdot 83 \\
74 \cdot 24 \pm 4 \cdot 38 \\
28 \cdot 15 \pm 2 \cdot 20 \\
43 \cdot 27 \pm 2 \cdot 22 \\
37 \cdot 00 \pm 2 \cdot 34\end{array}$ & $\begin{array}{l}+57 \\
+42 \\
+197 \\
+110 \\
-8\end{array}$ & $\begin{array}{l}<0.01 \\
<0.01 \\
<0.01 \\
<0.01 \\
<0.5\end{array}$ \\
\hline
\end{tabular}

Table I Numerical vaiues of 24-hour gastric secretion from the Heidenhain pouches of five dogs before and after mesenteric denervation

Cockel, and Lee, 1969). In the present study a continuous infusion of pentagastrin was used and emulsified olive oil was administered into the proximal jejunum. Denervation of the small intestine by transection of the entire small bowel mesentery appeared clearly to affect the 'enterogastrone' mechanism. In the vagally innervated main stomach the inhibitory effect of fat in the intestine was almost completely abolished at these dose levels of gastrin and fat. There was no significant change in the 


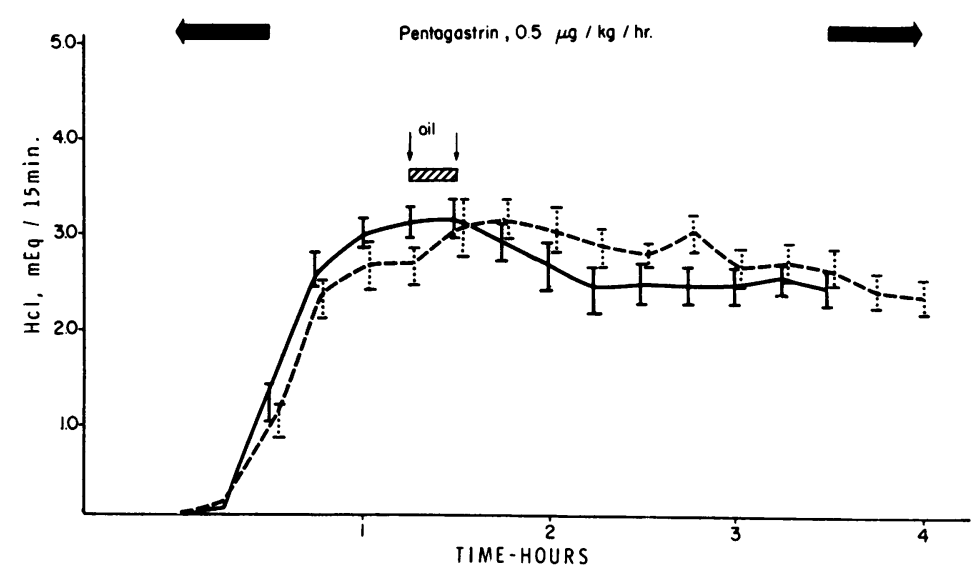

FIG. 4. Inhibitory effect of intrajejunal instillation of $15 \mathrm{ml}$ of emulsified olive oil on the pentagastrin-stimulated gastric fistula secretion after mesenteric denervation. Mean of 19 control (broken line) and 29 oil experiments (solid line).

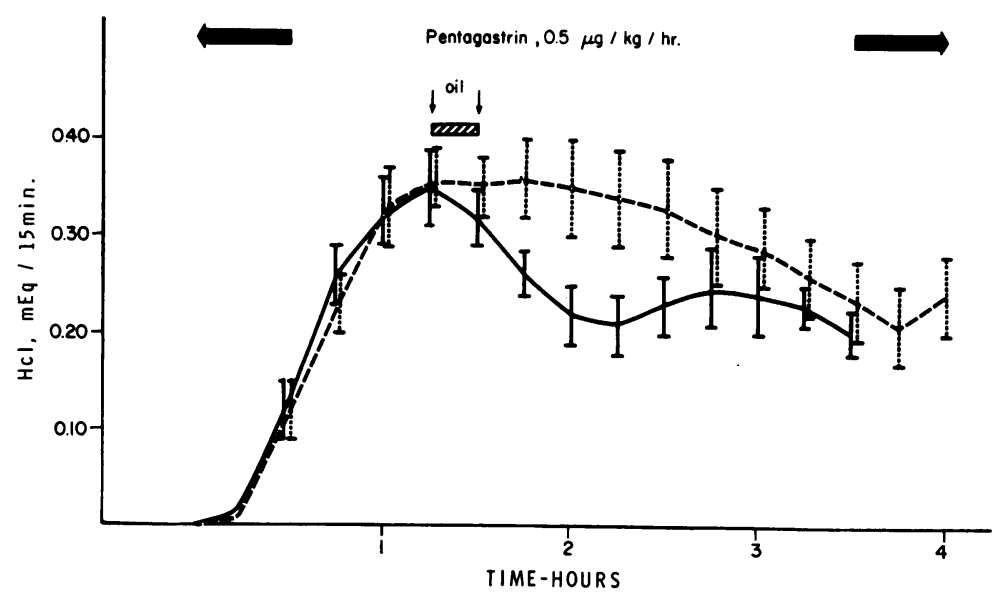

FIG. 5. Inhibitory effect of intrajejunal instillation of $15 \mathrm{ml}$ of emulsified olive oil on the pentagastrin-stimulated Heidenhain pouch secretion after mesenteric denervation. Mean of 14 control (broken line) and 22 oil experiments (solid line).

\begin{tabular}{|c|c|c|c|c|c|c|c|c|c|c|}
\hline \multirow[t]{3}{*}{ Dog } & \multicolumn{5}{|c|}{ Gastric Fistula } & \multicolumn{5}{|c|}{ Heidenhain Pouch } \\
\hline & \multicolumn{2}{|l|}{ Control } & \multicolumn{2}{|c|}{ After Denervation } & \multirow[t]{2}{*}{$P$} & \multicolumn{2}{|l|}{ Control } & \multicolumn{2}{|c|}{ After Denervation } & \multirow[t]{2}{*}{$P$} \\
\hline & $\begin{array}{l}\text { No. of } \\
\text { Experiments }\end{array}$ & $\%$ Inhibition & $\begin{array}{l}\text { No. of } \\
\text { Experiments }\end{array}$ & $\%$ Inhibition & & $\begin{array}{l}\text { No. of } \\
\text { Experiments }\end{array}$ & $\%$ Inhibition & $\begin{array}{l}\text { No. of } \\
\text { Experiments }\end{array}$ & $\%$ Inhibition & \\
\hline $\begin{array}{l}\mathbf{A} \\
\mathbf{B}\end{array}$ & $\begin{array}{l}6 \\
5\end{array}$ & $\begin{array}{l}78 \cdot 3 \pm 4 \cdot 3 \\
76 \cdot 3 \pm 15 \cdot 4\end{array}$ & $\begin{array}{l}5 \\
3\end{array}$ & $\underline{41 \cdot 2} \pm 15 \cdot 5$ & $\begin{array}{l}<0.05 \\
<0.01\end{array}$ & $\begin{array}{l}3 \\
5\end{array}$ & $\begin{array}{l}37 \cdot 2 \pm 13 \cdot 1 \\
83 \cdot 8 \pm 6 \cdot 1\end{array}$ & $\begin{array}{l}5 \\
3\end{array}$ & $\begin{array}{l}34 \cdot 2 \pm 16 \cdot 6 \\
67 \cdot 7 \pm 11 \cdot 0\end{array}$ & $\begin{array}{l}0.8 \\
0.3\end{array}$ \\
\hline C & 4 & $72 \cdot 1 \pm 16 \cdot 5$ & 2 & $59.0 \pm 5.5$ & $<0.7$ & & & & & \\
\hline D & 5 & $83.0 \pm 3.7$ & 11 & $50 \cdot 6 \pm 9.1$ & $<0.01$ & 3 & $41.5 \pm 8.0$ & 7 & $51.5 \pm 5.0$ & $0 \cdot 3$ \\
\hline $\mathbf{E}$ & 5 & $92.5 \pm 3.0$ & 5 & $18.9 \pm 10.9$ & $<0.01$ & 4 & $84.4 \pm 7.4$ & 7 & $42.8 \pm 9.2$ & $<0.01$ \\
\hline
\end{tabular}

Table II Percentage maximal inhibitory effect of emulsified olive oil on pentagastrin-stimulated gastric fistula and Heidenhain pouch secretion before (control) and after mesenteric denervation 


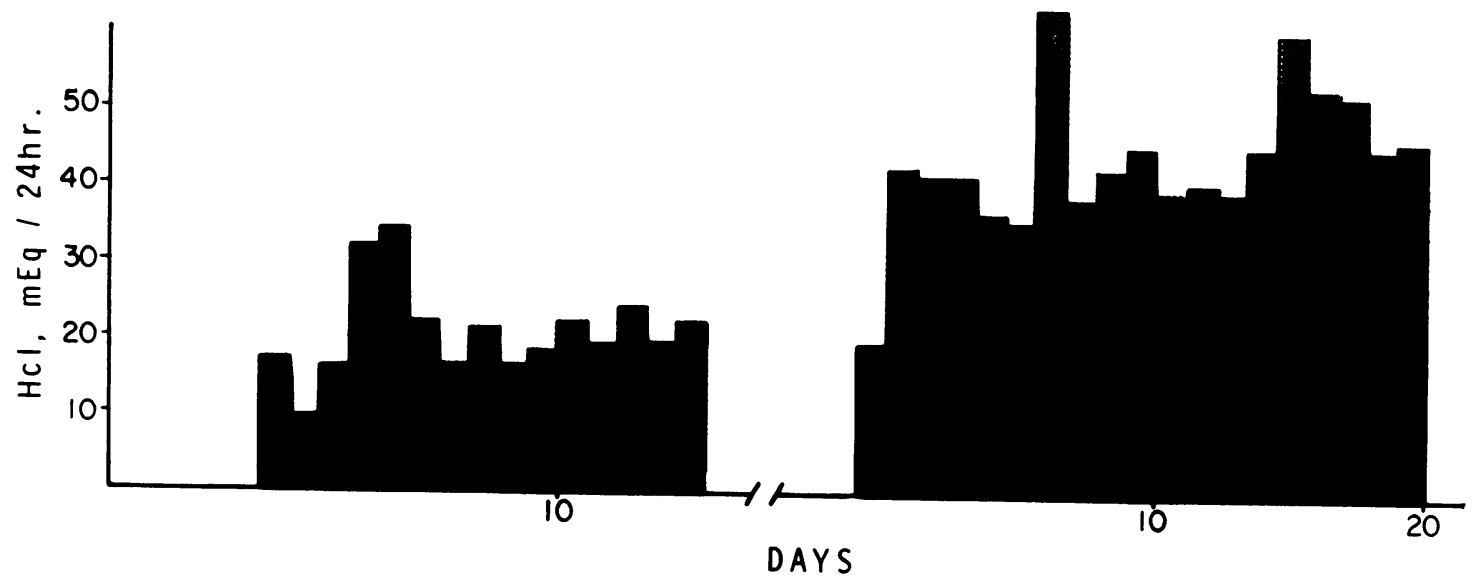

FIG. 6. Twenty-four-hour secretion from the Heidenhain pouch of one dog D before (left) and after (right) mesenteric denervation.

inhibition of Heidenhain pouch secretion. Postoperative changes in the intestine seem an unlikely explanation in view of the normal gross and microscopic appearance of the intestinal wall including the mucosa. There was no evidence of vascular insufficiency or lymphatic obstruction. Also, such an effect on the intestine would be expected to reflect equally in the inhibition of gastric fistula and Heidenhain pouch.

Another possible explanation would be that the autonomic nervous system is important in the formation or release of the hormone enterogastrone. This would be supported by our finding that the Heidenhain pouch secretion over a period of 24 hours on the standard dietary intake increased after intestinal denervation. Other investigators also have reported an increase in gastric secretion following extragastric vagotomy or posterior selective vagotomy (Landor, 1964; Kelly, Nyhus, and Harkins, 1964; Middleton, Kelly, Nyhus, and Harkins, 1965). A reduction in enterogastrone, however, would be expected to reduce the inhibition of both the gastric fistula and the Heidenhain pouch secretion. In fact, the vagally denervated pouch might be expected to be less responsive to an inhibitory influence than the vagally innervated stomach. Gastric secretory inhibition due to acid in the duodenum is more effective in a vagally innervated pouch (Code and Watkinson, 1955). Halvorson, Middleton, Bibler, Harkins, and Nyhus (1966) found that vagal innervation of the intestine did not influence the inhibition produced by fat in the intestine. However, they used histamine as a gastric secretory stimulant and also gave a much larger volume of fat.
The remaining explanation is that efferent fibres in the vagus nerves to the stomach are important in the enterogastrone mechanism. It seems unlikely that this humoral agent acts centrally and we would suggest instead that there is an inhibitory tonus in some vagus efferent fibres which acts synergistically with the humoral agent we call enterogastrone.

This work was supported by N.I.H. grant no. AM2372.

The authors wish to thank Mr William J. Rush Jr. for his technical assistance.

\section{References}

Bibler, D. D., Harkins, H. N., and Nyhus, L. M. (1966). Inhibitory effect of fat in the duodenum and upper small intestine on exogenous gastrin-stimulated gastric secretion. Surgery, 60, 844-847.

Code, C. F., and Watkinson, G. (1955). Importance of vagal innervation in the regulatory effect of acid in the duodenum on gastric secretion of acid. J. Physiol. (Lond.), 130, 233-252.

Debas, H. T., Bedi, B. S., Gillespie, G., and Gillespie, I. E. (1969) Mechanisms by which fat in the upper small intestine inhibits gastric acid. Gastroenterology, 56, 483-487.

Dragstedt, L. R., Haymond, H. E., and Ellis, J. C. (1933). Cannula gastrostomy and enterostomy. Surg. Gynec. Obstet., 56, 799 801.

Gregory, R. A. (1950). Some factors influencing the passage of fluid through intestine loops in dogs. J. Physiol. (Lond.), 111, 119. 137.

Gregory, R. A., and Tracy, H. J. (1959). The action of enterogastrone on gastric secretion. J. Physiol. (Lond.), 149, 58-59P.

Halvorson, H. C., Middleton, M. D., Bibler, D. D., Jr., Harkins, H. N., and Nyhus, L. M. (1966). Influence of the vagus nerve on the inhibitory effect of fat in the duodenum. Amer. J. dig. Dis., 11, 911-917.

Johnson, L. R., and Grossman, M. I. (1969). Effects of fat, secretin, and cholecystokinin on histamine-stimulated gastric secretion. Amer. J. Physiol., 216, 1176-1179. 
Kelly, K. A., Nyhus, L. M., and Harkins, H. N. (1964). The vagal nerve and the intestinal phase of gastric secretion. Gastroenterology, 46, 163-166.

Konturek, S., and Grossman, M. I. (1965). Effect of perfusion of intestinal loops with acid, fat, or dextrose on gastric secretion. Gastroenterology, 49, 481-489.

Kosaka, T., and Lim, R. K. S. (1929-30). Demonstration of the humoral agent in fat inhibition of gastric secretion. Proc. Soc. exp. Biol. (N.Y.), 27, 890-891.

Landor, J. H. (1964). The effect of extragastric vagotomy on Heidenhain pouch secretion in dogs. Amer. J. dig. Dis., 9, 256-562.

Middleton, M. D., Kelly, K. A., Nyhus, L. M., and Harkins, H. N. (1965). Selective vagal effects on the intestinal phase of gastric secretion. Gut, 6, 296-300.
Pavlov, I. P. (1910). The Work of the Digestive Glands, 2nd ed., translated by W. H. Thompson, p. 122. Griffin: London.

Sircus, W. (1958). Studies on the mechanisms in the duodenum inhibiting gastric secretion. Quart. J. exp. Physiol., 43, 114-133.

Snedecor, E. W., and Cochran, W. E. (1967). Statistical Methods, 6th ed. Iowa State University Press, Ames, Iowa.

Swan, K. E., Konturek, S. J., Jacobson, E. D., and Grossman, M. I. (1966). Inhibition of gastric secretion and motility by fat in the intestine. Proc. Soc. Exp. Biol. (N.Y.), 121, 840-844.

Thomas, J. E. (1941). An improved cannula for gastric and intestinal fistulas. Proc. Soc. exp. Biol. (N.Y.), 46, 260-261.

Windsor, C. W. O., Cockel, R., and Lee, M. J. R. (1969). Inhibition of gastric secretion in man by intestinal fat infusion. Gut, 10 , 135-142.

\section{The December 1970 Issue}

\section{THE DECEMBER 1970 ISSUE CONTAINS THE FOLLOWING PAPERS}

Hereditary angioneurotic oedema: an unusual case of recurring abdominal pain EDWARD J. FELLER, HOWARD M. SPIRO, AND LEONARD A. KATZ

Studies of the effect of metoclopramide and apomorphine on gastric emptying and secretion in man N. RAMSBOTTOM AND J. N. HUNT

Observations on gastric acid output by a three-hour histamine infusion test using maximal doses on patients with duodenal ulcer and in normal controls R. M. HECTOR AND J. F. WEBB

Peptic ulceration in Crohn's disease (regional enteritis) J. F. FIELDING AND W. T. COOKE

Crohn's disease of the stomach and duodenum J. F. FIELDING, D. K. M. TOYE, D. C. BETON, AND W. T. COOKE

Electron microscopy of myenteric nerves in Hirschsprung's disease and in normal bowel E. R. HOWARD AND J. R. GARRETT

A new method of measuring the rate of shedding of epithelial cells from the intestinal villus of the rat RUFUS M. CLARKE
The influence of sex, body weight, and renal function on the xylose test MARTIN J. KENDALL AND SHEILA NUTTER

Reversible nicotinamide-deficiency encephalopathy in a patient with jejunal diverticulosis S. TABAQCHALI AND C. PALLIS

Acalculous adenomyomatosis of the gallbladder G. BEVAN

Occurrence of an abnormal lipoprotein in patients with liver disease A. ROss, G. M. MURPHY, P. A. WILKINSON, G. L. MILLS, AND S. SHERLOCK

The action of sennosides and related compounds on human colon and rectum J. D. HARDCASTLE AND J. L. WILKINS

Progress report Lactulose S. G. ELKINGTON

Progress report Electrolyte absorption from the colon L. A. TURNBERG

Proceedings: British Society of Gastroenterology: 31st Annual General Meeting

Notes and activities

Copies are still available and may be obtained from the PUBLISHING MANAGER, BRITISH MEDICAL ASSOCIATION, TAVISTOCK SQUARE, LONDON, WC1H 9JR, price 17s. 6D. 